\title{
EFFECTS OF CHRONIC HYPERCAPNIA ON ELECTROLYTE AND ACID-BASE EQUILIBRIUM. I. ADAPTATION *
}

\author{
By ADOLF POLAK, GORDON D. HAYNIE, † RICHARD M. HAYS $\ddagger$ AND \\ WILLIAM B. SCHWARTZ §
}

(From the Department of Medicine, Tufts University School of Medicine, and the Pratt ClinicNew England Center Hospital, Boston, Mass.)

(Submitted for publication February 15, 1961 ; accepted March 13, 1961)

Although chronic respiratory acidosis is one of the commonest clinical disturbances of acicl-base balance, the process of adaptation which it induces has not been extensively investigated. Normal man tolerates prolonged exposure to high $\mathrm{CO}_{2}$ tensions poorly and is, therefore, not a suitable subject for study. Recent observations in the rat exposed to a high $\mathrm{CO}_{2}$ atmosphere $(1,2)$ have provided much valuable information, but no balance data are available in the dog, the animal which appears more closely to resemble man in its adjustment to other disturbances of acid-base equilibrium. For this reason, and in order to provide a basis for further investigations of chronic hypercapnia in the dog, the present studies of adaptation were undertaken.

\section{METHODS}

Eleven balance studies were carried out on 11 healthy female mongrel dogs weighing between 13 and $20 \mathrm{~kg}$. Observations were made during a 4- to 7-day control period and a 6- to 15-day period of exposure to 10 to 13 per cent carbon dioxide $\left(\mathrm{CO}_{2}\right.$ period $)$.

The studies were carried out with the dogs in metabolic cages maintained at a temperature of approximately $15^{\circ} \mathrm{C}$ inside a small, ventilated room. The cages were covered with a plastic canopy which was left open during the control period. During the $\mathrm{CO}_{2}$ period the canopy was closed, and a gas mixture of $\mathrm{CO}_{2}, \mathrm{O}_{n}$, and compressed air was delivered into it. The ratio of the gases delivered was regulated manually. The $\mathrm{CO}_{2}$ content of the cages was monitored frequently with a Kwik-Check carbon dioxide analyzer (Burrell Corp.),

* Supported in part by grants from the National Heart Institute (H-759 and HTS-5309), the American Heart Association and the Life Insurance Medical Research Fund.

$\dagger$ Medical Foundation Research Fellow, The Medical Foundation of Metropolitan Boston, Inc.

$\ddagger$ Public Health Research Fellow of the National Heart Institute.

$\S$ Established Investigator, American Heart Association. which was standardized with gas mixtures whose composition had been determined by the Scholander method. The oxygen content was determined by a Beckman model $\mathrm{C}$ oxygen analyzer.

On the first day of the $\mathrm{CO}_{2}$ period, the $\mathrm{CO}_{2}$ content of the cage atmosphere was increased to approximately 10 per cent over a period of 3 to 6 hours. Over the next 1 to 2 days the level was raised slowly to the desired range of 11 to 13 per cent. The oxygen concentration was maintained at $20 \pm 3$ per cent throughout.

The dogs were removed from the cages each morning for weighing, feeding, collection of urine and feces, cage cleaning, and (on most mornings) arterial blood sampling. During the $\mathrm{CO}_{2}$ period they were also removed in the evening so that the daily diet could be fed in two portions. The total time out of the high $\mathrm{CO}_{2}$ atmosphere on each of these days was about 30 minutes. In order to obtain data on the early adaptation to uninterrupted respiratory acidosis, 9 of the dogs were given their entire diet for the first day of the $\mathrm{CO}_{2}$ period 2 to 3 hours before the $\mathrm{CO}_{2}$ tension was raised, and they were then left undisturbed for 24 hours.

A synthetic diet was given, consisting (in per cent) of 55 water, 14 casein, 1.5 agar, 8 hydrogenated vegetable oils, 7.5 dextrose, 14 dextrin, and supplementary vitamins. To each $100 \mathrm{~g}$ of diet, $9 \mathrm{mEq}$ of potassium was added as neutral phosphate (4 parts $\mathrm{K}_{2} \mathrm{HPO}_{4}, 1 \mathrm{KH}_{2} \mathrm{PO}_{4}$ ). The diet was homogenized with 1.5 times its weight of water shortly before feeding. The homogenate was fed in a pan during the control and recovery periods, but during the $\mathrm{CO}_{2}$ period it had to be tube-fed because of anorexia. Rejected food was weighed and any vomitus was either re-fed or weighed and analyzed. The sodium, potassium, chloride, and nitrogen content of the diet was checked frequently by analysis.

The dogs received $30 \mathrm{~g}$ of diet (75 $\mathrm{g}$ of homogenate) per $\mathrm{kg}$ of body weight per day. In order to study the effects of restriction of sodium and of chloride, the animals were divided into 3 groups whose diet was identical except in the following respects: 1) 5 dogs received 50 to $70 \mathrm{mEq}$ of sodium and chloride daily (high-salt group): 2) 5 dogs received approximately $5 \mathrm{mEq}$ of sodium and $3 \mathrm{mEq}$ of chloride daily, the intrinsic sodium and chloride content of the synthetic diet (low-salt group) ; 3) 1 dog was studied on a diet identical with that of the lowsalt group except that sufficient potassium chloride was added in lieu of potassium phosphate to raise the daily chloride intake to $13 \mathrm{mEq}$. 


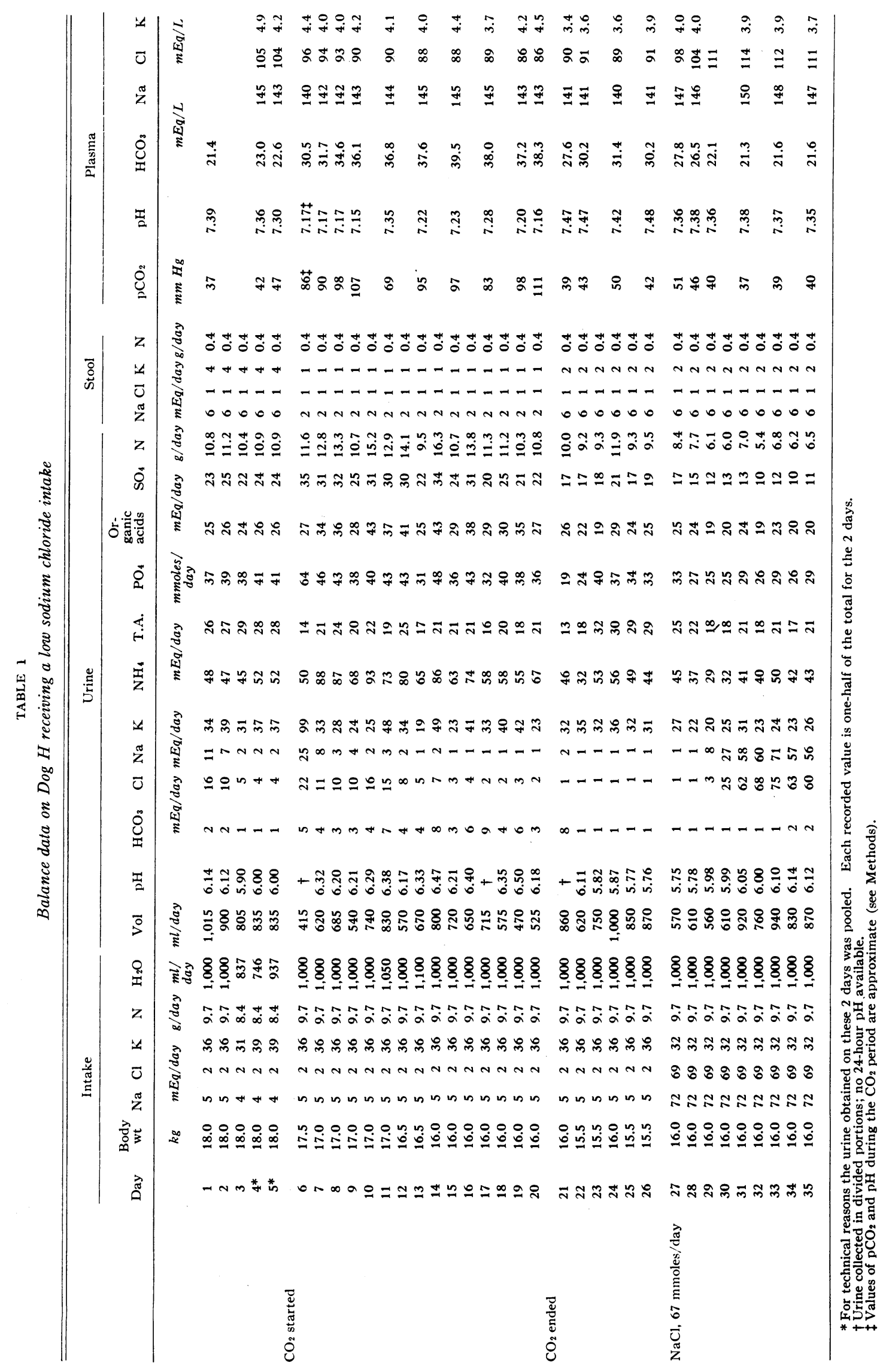




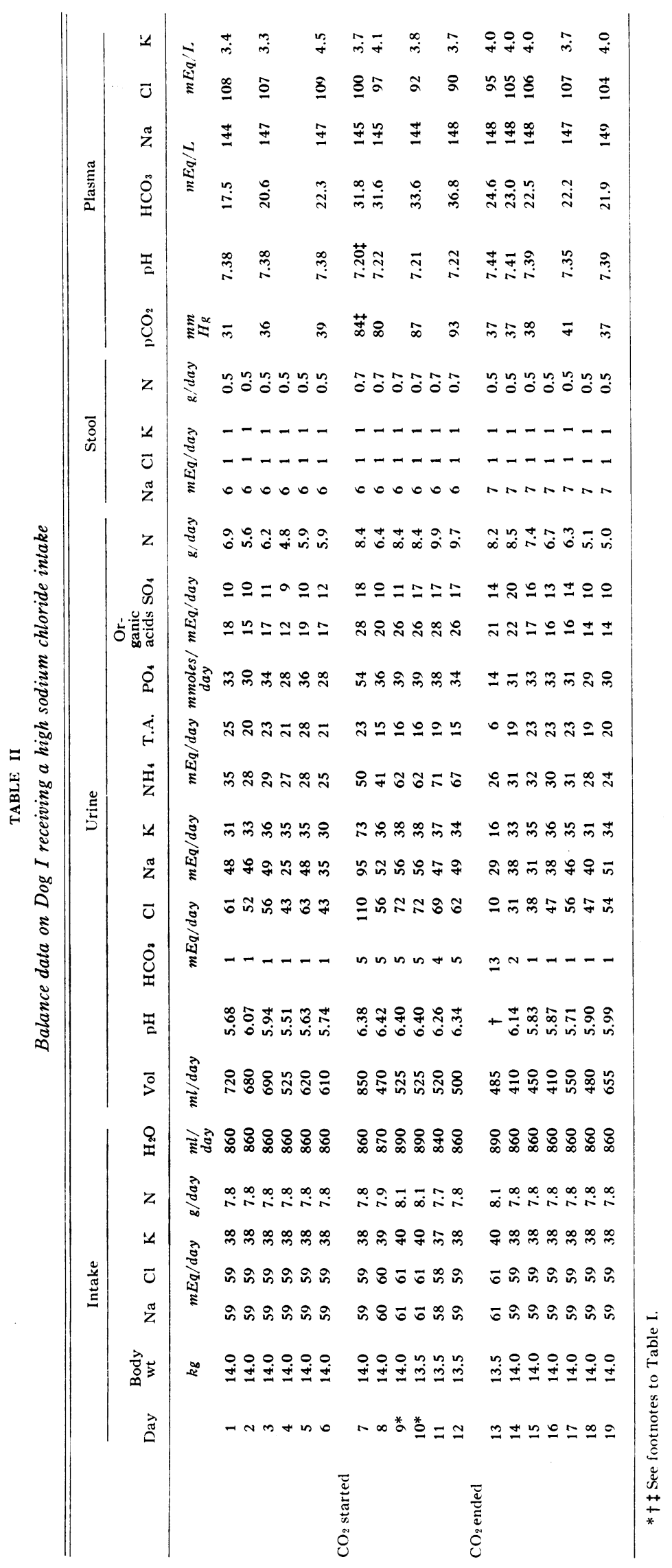


The data on acid-base balance obtained in the third study were fully comparable with those obtained in the studies on dogs of the low-salt group, and will therefore be included with them in the Results section. Twenty-two additional dogs were studied during 1 day of exposure to $\mathrm{CO}_{2}$, in order to obtain further data on bicarbonate excretion. Some animals were fed the synthetic diet while others were given a meat diet.

The urine drained into bottles containing mineral oil and thymol chloroform over a siliconized metal surface. The system was tested frequently with water and gave over 97 per cent recovery. Collections were ended at 9 a.m. each day, and volume, $\mathrm{pH}$, and $\mathrm{CO}_{2}$ content were determined promptly.

Blood samples of approximately $25 \mathrm{ml}$ were drawn from the femoral artery with heparinized syringes. During the $\mathrm{CO}_{2}$ period blood samples were taken while the dogs breathed 12 per cent carbon dioxide in 20 per cent oxygen and 68 per cent nitrogen through a nonrebreathing valve mask in order to achieve conditions similar to those in the cage. It is apparent, however, that these values for blood $\mathrm{pH}$ and $\mathrm{pCO}_{2}$ can be taken only as approximations.

Feces were collected and pooled for each control, $\mathrm{CO}_{2}$ and recovery period. The collections were begun and ended 24 hours later than the corresponding experimental period.

The analytic procedures have been described in a previous paper (3). The electrolyte content of diet, stool, and vomitus was determined on nitric acid extracts. Titratable acid was taken as the sum of the calculated contributions of phosphate and organic acids (4).

The daily balance was calculated as the net intake

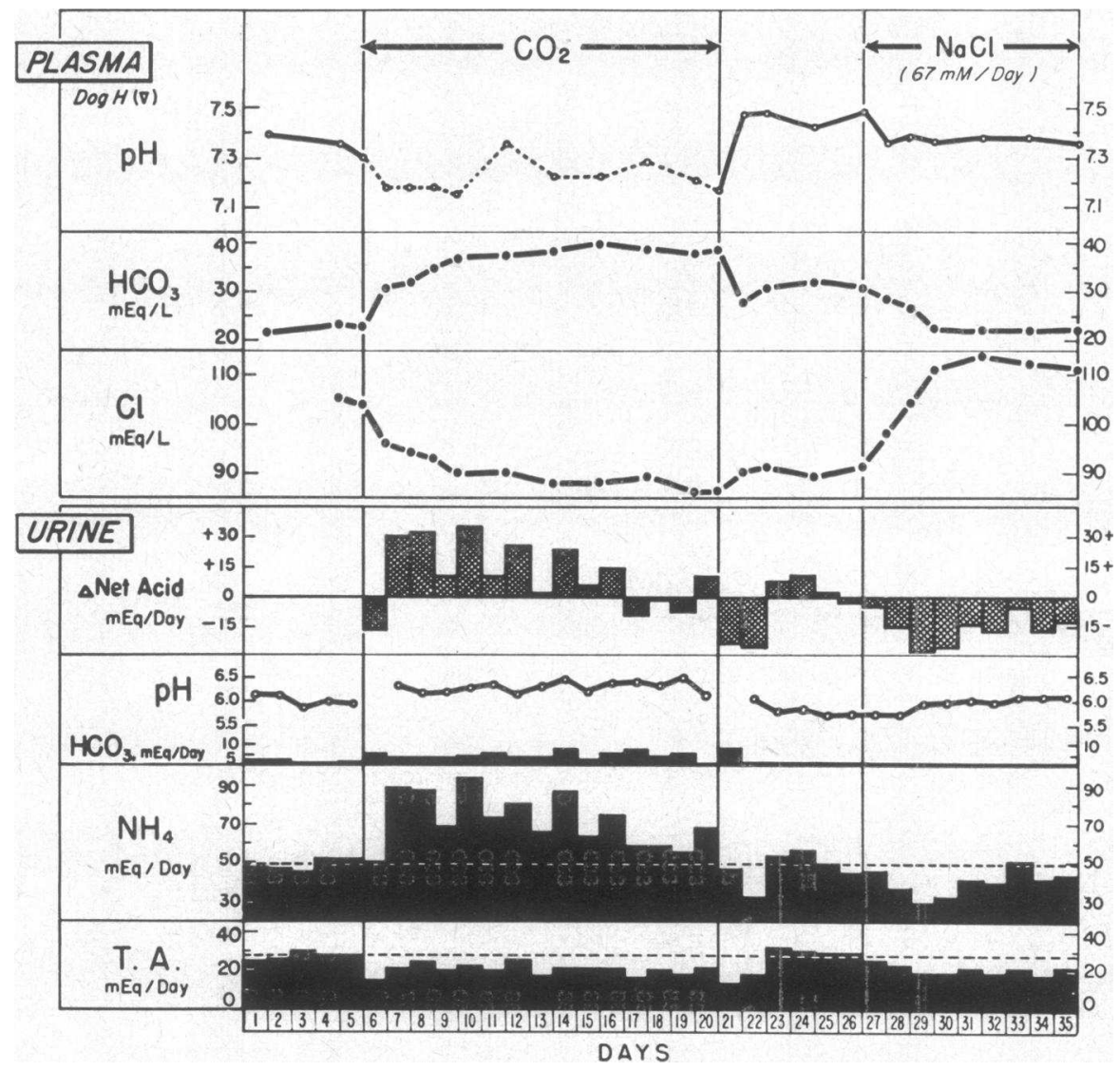

Fig. 1. Changes in acid-base equilibrium and serum chloride concentration DURING EXPOSURE TO A HIGH $\mathrm{CO}_{2}$ ATMOSPHERE IN A DOG ON A LOW SODIUM CHLORIDE INTAKE. The dashed horizontal lines represent the mean daily excretion during the control period. The values for net acid excretion (ammonium + titratable acid - bicarbonate) represent changes from the mean daily excretion during the control period. The values for plasma $\mathrm{pH}$ during exposure to $\mathrm{CO}_{2}$ are shown with a dashed line since they are only approximate (see text). Urine $\mathrm{pH}$ values are not shown for the 2 days during which divided collections were made. The portion of the figure depicting the changes after withdrawal from $\mathrm{CO}_{2}$ is discussed in the following paper (5). 


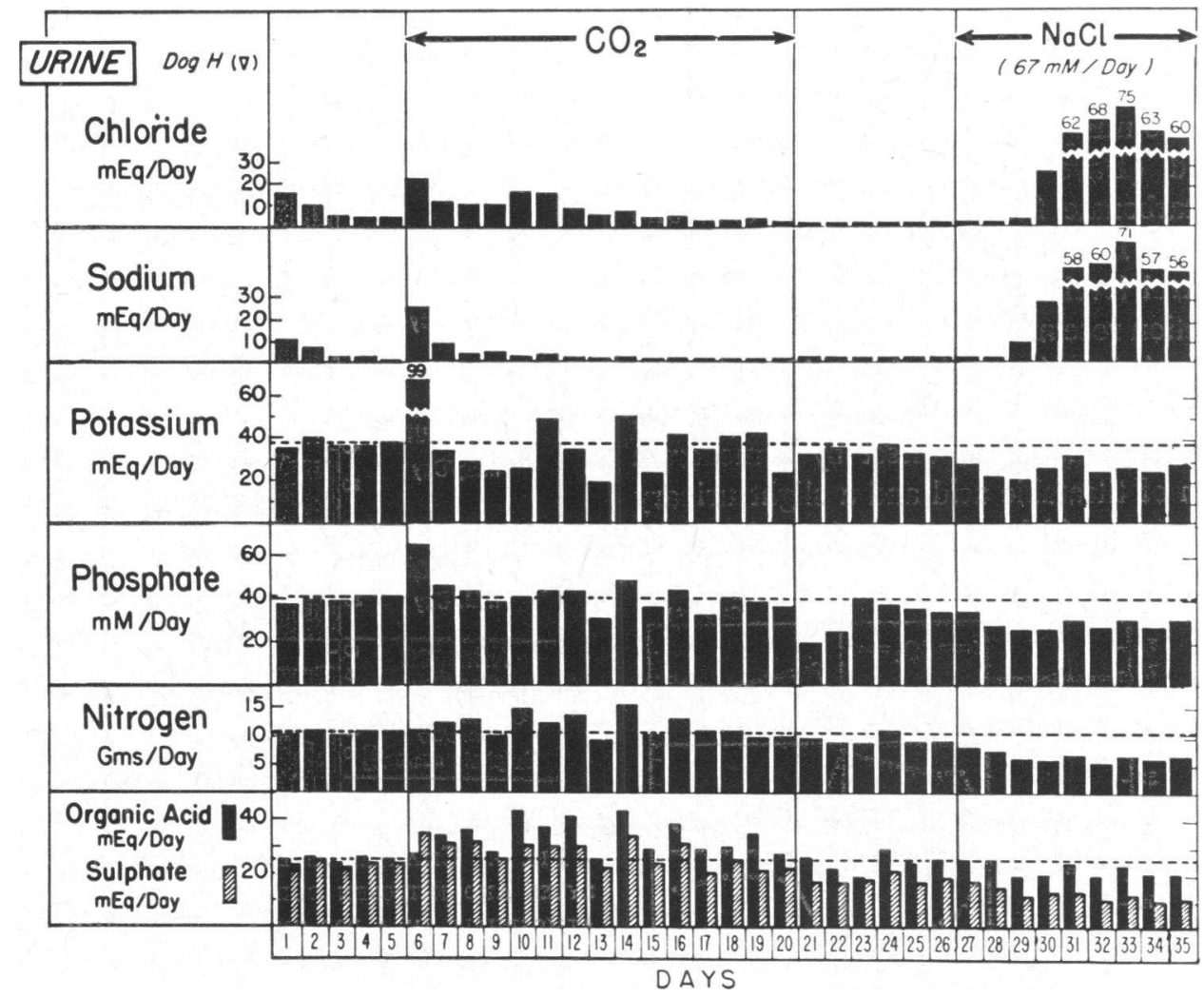

Fig. 2. Changes in the excretion of URinary electrolytes and Nitrogen during exPOSURE to A High CO. ATMOSPhERE IN A DOG ON A LOW SODIUM CHLORIDE intaKe. The dashed horizontal lines represent the mean daily excretion during the control period. The portion of the figure depicting the changes after withdrawal from $\mathrm{CO}_{2}$ is discussed in the following paper (5).

minus the combined output in the urine and stools. The change in net external balance (or " $\Delta$ balance"), to which frequent reference will be made in presenting and discussing the results, was calculated as the difference between the balance on an experimental day and the mean daily balance during the control period. However, in the case of the dogs on a low-salt intake, which were often not in a state of balance until the last control day, the balances of sodium and chloride on that day were used instead of the mean control values in the calculation of the $\Delta$ balance. In calculating a correction for potassium excretion due to changes in nitrogen balance, a value of $2.7 \mathrm{mEq}$ potassium per $\mathrm{g}$ of nitrogen was used.

\section{RESULTS}

\section{A. Representative studies on low- and high-salt intake}

The results of a typical study on a dog (Dog $\mathrm{H})$ receiving a low intake of sodium and chloride are shown in Table I, and the chief parameters relevant to acid-base and electrolyte balance are depicted in Figures 1 and 2. Observations made during a subsequent recovery period are included in Table $I$ and Figures 1 and 2 but will be considered in the succeeding paper (5).

Figure 1 shows that the plasma bicarbonate, which at the end of the control period was 22.6 $\mathrm{mEq}$ per $\mathrm{L}$, had risen to $30.5 \mathrm{mEq}$ per $\mathrm{L}$ after 1 day of exposure to $\mathrm{CO}_{2}$ (Day 6). It then climbed gradually to 37.6 by the end of Day 8, and fluctuated between 37.2 and $39.5 \mathrm{mEq}$ per $\mathrm{L}$ during the rest of the 15-day period. Urinary excretion of ammonium on the first day of the $\mathrm{CO}_{2}$ period did not change from the mean control level, while titratable acid fell, and there was a slight loss of bicarbonate. Thus, the rise of nearly $8 \mathrm{mEq}$ per $\mathrm{L}$ in plasma bicarbonate on the first day of the $\mathrm{CO}_{2}$ period was actually accompanied by a decrease in net acid excretion. By contrast, the 
rise of $7 \mathrm{mEq}$ in plasma bicarbonate during the next 7 days of the period ( 7 through 13) was accompanied by a cumulative increment in net acid excretion of $130 \mathrm{mEq}$. During the remainder of the $\mathrm{CO}_{2}$ period (Days 14 through 20), while the plasma bicarbonate fluctuated between 37.2 and $39.5 \mathrm{mEq}$ per L, net acid excretion gradually fell to the control level. It will be seen that ammonium excretion rose markedly on the second day of the $\mathrm{CO}_{2}$ period and remained significantly elevated thereafter, but part (and late in the period, all) of this increment was offset by a moderate suppression of titratable acid and a slight urinary bicarbonate loss which persisted throughout the

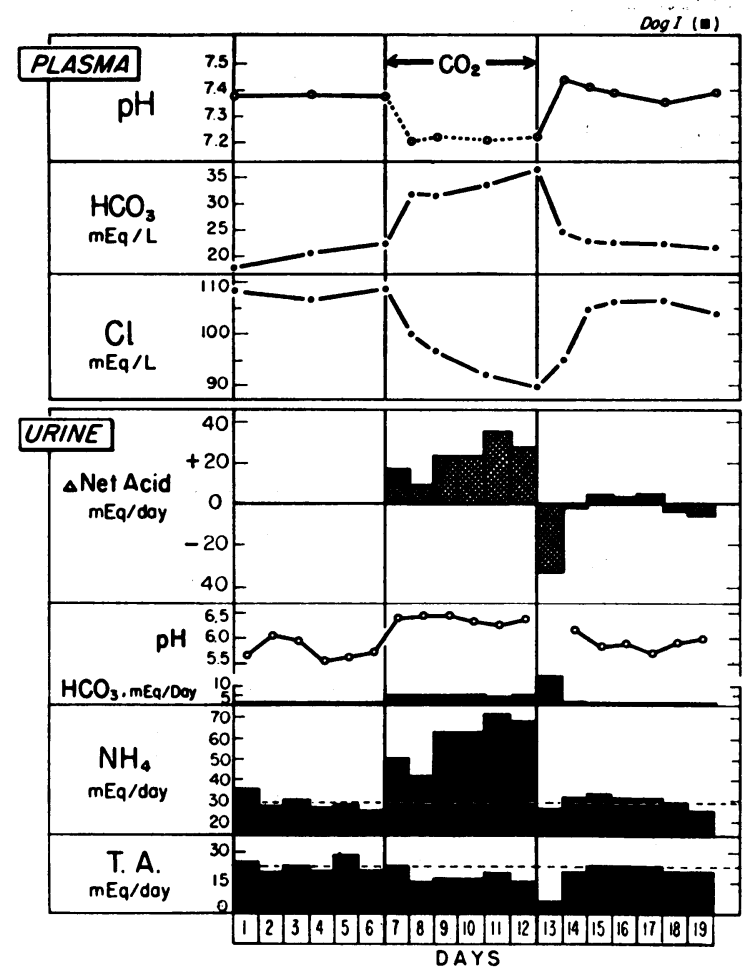

Fig. 3. Changes in ACID-Base equilibrium AND SERUM CHLORIDE CONCENTRATION DURING EXPOSURE TO A HIGH $\mathrm{CO}_{2}$ ATMOSPhere IN A DOG ON A HIGH SODIUM CHLORIDE INTAKE. The dashed horizontal lines represent the mean daily excretion during the control period. The values for net acid excretion (ammonium + titratable acid - bicarbonate) represent changes from the mean daily excretion during the control period. The values for plasma $\mathrm{pH}$ during exposure to $\mathrm{CO}_{2}$ are shown with a dashed line since they are only approximate (see text). Urine $\mathrm{pH}$ is not shown for Day 13, during which divided urine collections were made. The portion of the figure depicting the changes after withdrawal from $\mathrm{CO}_{2}$ is discussed in the following paper (5).

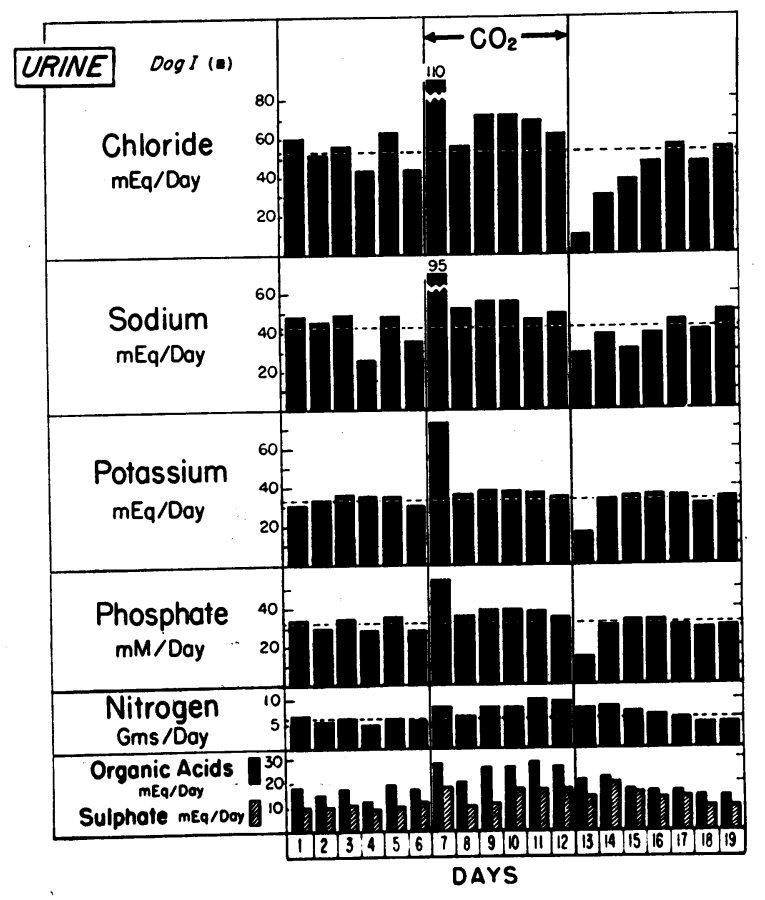

Fig. 4. Changes in excretion of URinary electroLYTES AND NITROGEN DURING EXPOSURE TO A HIGH CO, ATMOSPHERE IN A DOG ON A HIGH SODIUM CHLORIDE INTAKE. The dashed horizontal lines represent the mean daily excretion during the control period. The portion of the figure depicting the changes after withdrawal from $\mathrm{CO}_{2}$ is discussed in the following paper (5).

period. The urinary $\mathrm{pH}$ (range 6.17 to 6.50 ) was slightly above control values throughout the period.

Table I and Figure 2 show a sharp rise in the excretion of chloride, sodium, potassium, and phosphate on the first day of the $\mathrm{CO}_{2}$ period (Day 6). Plasma chloride fell by $8 \mathrm{mEq}$ per L (Table I).

The urinary chloride output remained significantly elevated from the second day of the $\mathrm{CO}_{2}$, period through the sixth (Days 7 through 13), averaging $10 \mathrm{mEq}$ above the final control level. During these 7 days the plasma chloride fell by a further $8 \mathrm{mEq}$, while the plasma bicarbonate rose $7.1 \mathrm{mEq}$. The urinary sodium excretion returned to a low level more quickly than did the chloride excretion, while the plasma sodium level remained steady.

Urinary phosphate, like urinary sodium, had returned to its control level after 2 to 3 days of exposure to $\mathrm{CO}_{2}$ and remained close to that level subsequently. Urinary potassium fell promptly below the control level from its peak on the first 
day and remained depressed for Days 7 through 10. Cumulative $\Delta$ potassium balance for the whole $\mathrm{CO}_{2}$ period totaled $+10 \mathrm{mEq}(+36 \mathrm{mEq}$ after correction for nitrogen balance). The serum potassium showed no significant change.

Table I shows that the nitrogen balance, which averaged $-2.3 \mathrm{~g}$ per day in the control period, became somewhat more negative in the $\mathrm{CO}_{2}$ period, averaging $-3 \mathrm{~g}$ per day. It can be seen that the output of organic acids and sulfate also rose, but by the last 4 days of the $\mathrm{CO}_{2}$ period, sulfate and organic acid as well as nitrogen had returned approximately to the control range. The hematocrit fell from 55 to 47 (over $300 \mathrm{ml}$ of blood was drawn).

The results of a study on Dog I, receiving a high intake of sodium and chloride, are shown in Table II, and the chief parameters relevant to acidbase and electrolyte balance are depicted in Figures 3 and 4 . The changes were closely similar to those seen in the low-salt study (Table I and Figures 1 and 2) and will not be described in detail. Comparisons of the high- and low-salt groups, instead, are considered below.

\section{B. Collective data}

This section summarizes the observations made in the 11 balance studies ( 5 on a high-salt and 6 on a low-salt diet).

1. Acid-base balance. At the end of the control period, the range of plasma bicarbonate concen-

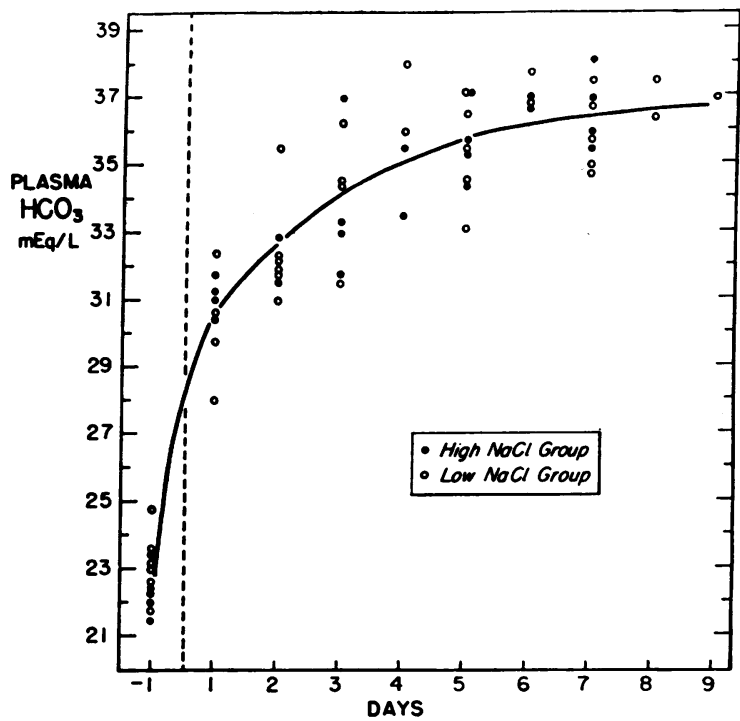

Fig. 5. EFfect on plasma bicarbonate concentraTION OF EXPOSURE TO A HIGH $\mathrm{CO}_{2}$ ATMOSPhere. Day -1 refers to the last day of the control period. The curved line through the points was drawn by inspection. Note that the level of sodium chloride intake appears to have no influence on the plasma bicarbonate values.

tration in the 11 dogs was 21.4 to $24.7 \mathrm{mEq}$ per $\mathrm{L}$ (mean 22.8). Figures 5 and 6 show that by the end of the first day of the $\mathrm{CO}_{2}$ period the plasma bicarbonate had risen by an average of $9.1 \mathrm{mEq}$ per L (range 8.0 to 9.8 ) in the high-salt group, and $7.1 \mathrm{mEq}$ per $\mathrm{L}$ (range 5.0 to 9.3 ) in the low-salt group. This constituted half or more of the rise that occurred during the entire $\mathrm{CO}_{2}$

TABLE III

$\Delta$ Cumulative balances during exposure to a high $\mathrm{CO}_{2}$ atmosphere

\begin{tabular}{|c|c|c|c|c|c|c|c|c|c|}
\hline Group & Dog & Days & $\mathrm{Cl}$ & $\mathrm{Na}$ & $\mathrm{Cl}-\frac{\mathrm{Na}}{1.3}$ & $\mathrm{~K}$ & $\begin{array}{l}\mathrm{K} \text { corr. } \\
\text { for } \mathrm{N}^{*}\end{array}$ & $\mathrm{~N}$ & $\begin{array}{c}\text { Cumula- } \\
\text { tive } \Delta \\
\text { net acid } \\
\text { excretiont }\end{array}$ \\
\hline & & & \multicolumn{2}{|c|}{$m E q$} & \multicolumn{2}{|c|}{$m E q$} & $m E q$ & $g$ & $m E q$ \\
\hline mign svacintake & $\begin{array}{l}\mathrm{G} \\
\mathrm{K} \\
\mathrm{I} \\
\mathrm{J} \\
\mathrm{S}\end{array}$ & $\begin{array}{l}7 \\
7 \\
6 \\
6 \\
8\end{array}$ & $\begin{array}{l}-51 \\
-\quad 74 \\
-119 \\
-\quad 64 \\
-17\end{array}$ & $\begin{array}{l}-\quad 9 \\
-\quad 43 \\
-100 \\
-\quad 31 \\
+\quad 7\end{array}$ & $\begin{array}{l}-44 \\
-41 \\
-42 \\
-40 \\
-12\end{array}$ & $\begin{array}{l}-68 \\
-24 \\
-52 \\
-18 \\
-43\end{array}$ & $\begin{array}{l}-45 \\
-14 \\
-7 \\
-18 \\
+32\end{array}$ & $\begin{array}{r}-9 \\
-4 \\
-17 \\
0 \\
-27\end{array}$ & $\begin{array}{l}+103 \\
+90 \\
+125 \\
+29 \\
+212\end{array}$ \\
\hline Low $\mathrm{NaCl}$ intake & $\begin{array}{l}\mathrm{H} \\
\mathrm{A} \\
\mathrm{B} \\
\mathrm{D} \\
\mathrm{F}\end{array}$ & $\begin{array}{r}15 \\
7 \\
7 \\
9 \\
7\end{array}$ & $\begin{array}{l}-74 \\
-79 \\
-88 \\
-83 \\
-41\end{array}$ & $\begin{array}{l}+31 \\
-\quad 19 \\
-36 \\
-\quad 27 \\
+\quad 2\end{array}$ & $\begin{array}{l}-98 \\
-64 \\
-60 \\
-62 \\
-43\end{array}$ & $\begin{array}{l}+10 \\
-38 \\
-39 \\
-78 \\
+\quad 1\end{array}$ & $\begin{array}{l}+36 \\
-6 \\
+27 \\
-50 \\
+25\end{array}$ & $\begin{array}{l}-11 \\
-12 \\
-24 \\
-11 \\
-8\end{array}$ & $\begin{array}{l}+181 \\
+96 \\
+223 \\
+149 \\
+168\end{array}$ \\
\hline
\end{tabular}

* $2.7 \mathrm{mEq}$ potassium/g nitrogen

$\dagger$ This value is not a balance but represents the change in net acid excretion. 


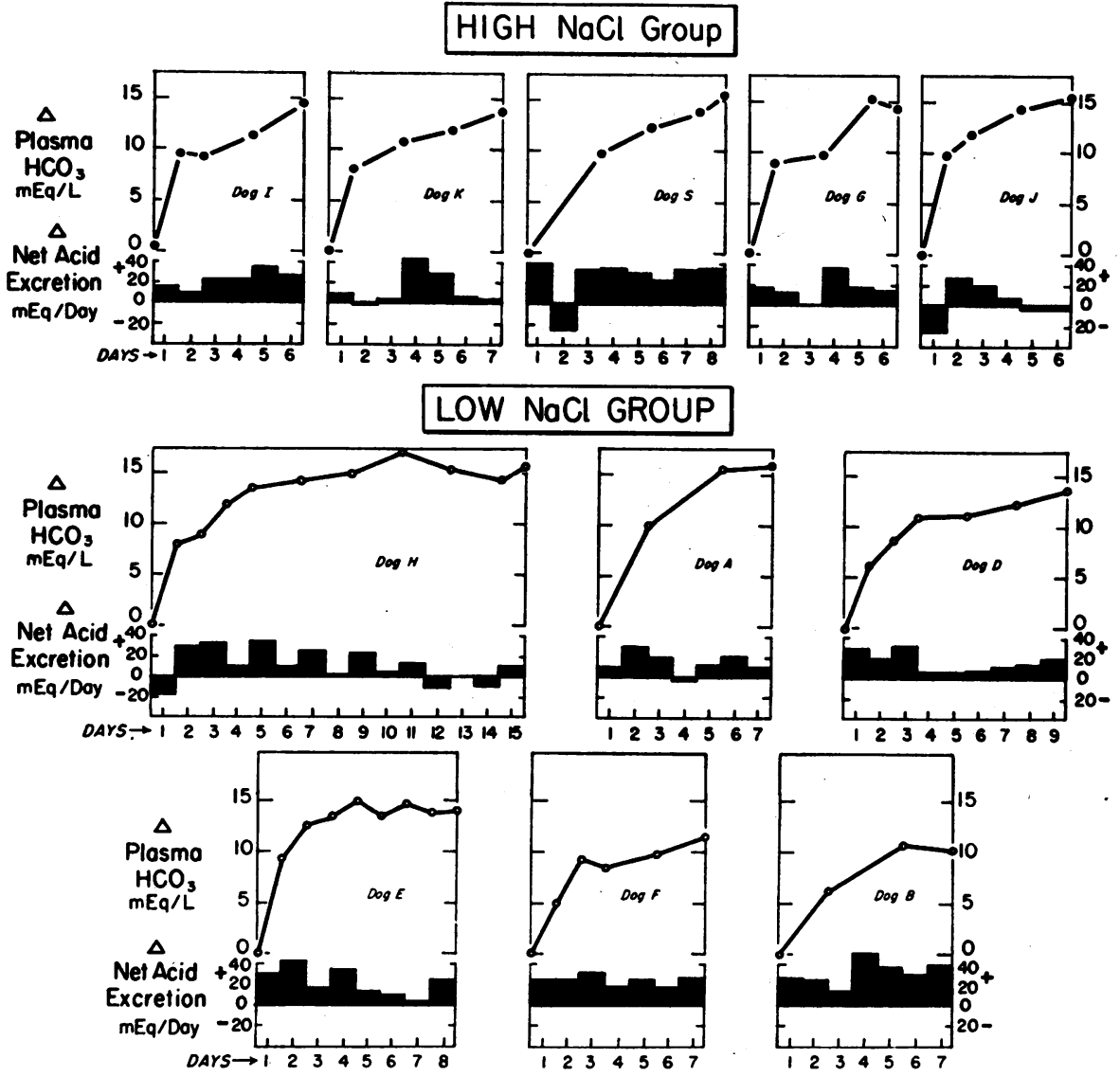

Fig. 6. Relationship BETWEen the RISE in PLASMa Bicarbonate concentration AND CHANGeS IN NET ACID EXCRETION DURING EXPOSURE TO A HIGH $\mathrm{CO}_{2}$ ATMOSPhere. Changes in plasma bicarbonate are calculated from the final control value. Changes in net acid excretion (ammonium + titratable acid-bicarbonate) are calculated from the mean control value.

period. Figure 6 shows the urinary net acid excretion (ammonia plus titratable acid minus bicarbonate). In 4 dogs there was no significant rise in the urinary net acid during the first day, and in 2 of these net acid excretion actually fell. In the remaining 7 dogs net acid excretion rose on the first day, but there was no relationship between the magnitude of the rise in plasma bicarbonate and the direction or magnitude of the change in net acid excretion. On the second and subsequent days of the $\mathrm{CO}_{2}$ period, the rate of rise in plasma bicarbonate decreased progressively, approaching a plateau between 35 and $38 \mathrm{mEq}$ per $L$ in a week. In every $\operatorname{dog}$ net acid excretion after the first day showed a cumulative increment which greatly exceeded the increment seen on the first day. With the exception of one animal, the cumulative increase in net acid excretion for the entire $\mathrm{CO}_{2}$ period (Table III) was far greater than would be needed to produce the observed rise in plasma bicarbonate, based on an assumed extracellular volume of 25 per cent of the body weight.

Figure 7 shows the changes in the three components of urinary net acid excretion separately and demonstrates that there was no apparent difference in the response of the high- and low-salt groups. The ammonium excretion rose above the mean control level on the first day in 8 of the 11 dogs. By the third day, ammonium excretion had risen in all dogs and remained elevated above control levels for the rest of the study. Urine 
$\mathrm{pH}$, which was in the range of approximately 5.5 to 6.0 during the control period, rose slightly to a range of 6.0 to 6.5 .

Titratable acid excretion rose on Day 1 in a few dogs, but in most dogs the excretion of titratable acid was unchanged or fell below control values. From the second day of the $\mathrm{CO}_{2}$ period onward, titratable acid was suppressed in almost every dog.

Urinary bicarbonate excretion (Figure 7), which during the control period averaged less than $1 \mathrm{mEq}$ per day, rose slightly (usually by 1 to $5 \mathrm{mEq}$ ) when the dogs were exposed to $\mathrm{CO}_{2}$ and remained slightly elevated. In the 22 additional brief studies on bicarbonate excretion, a much wider range of urinary bicarbonate increments was observed during the first day in $\mathrm{CO}_{2}$. In 9 animals excretion reached a level of 10 to $25 \mathrm{mEq}$, and in those dogs there was regularly a suppression of ammonium and titratable acid excretion.

2. Chloride, sodium, potassium, and phosphate. On the first day of exposure to $\mathrm{CO}_{2}$ the plasma chloride fell by an average of $8 \mathrm{mEq}$ in the highsalt and $7 \mathrm{mEq}$ in the low-salt group. The "mirror image" relationship between the curves describing changes in plasma chloride and plasma bicarbonate was maintained throughout the $\mathrm{CO}_{2}$ period in all the animals and is well illustrated in Figures 1 and 3.

Figure 8 shows the corresponding changes in the daily chloride and sodium balances. These changes can be interpreted as virtually equivalent to changes in the urinary excretion, because intake and fecal excretion remained nearly constant. On the first day of the $\mathrm{CO}_{2}$ period there was a significant increase in urinary chloride in all but 2 of the 10 dogs (these two dogs were exceptional in that their urine showed no significant change in electrolyte composition until the second and fourth days, respectively, of the $\mathrm{CO}_{2}$ period, although their plasma electrolyte levels did show characteristic changes on the first day). Subsequently, there was a progressively diminishing chloruresis, chloride excretion approaching the

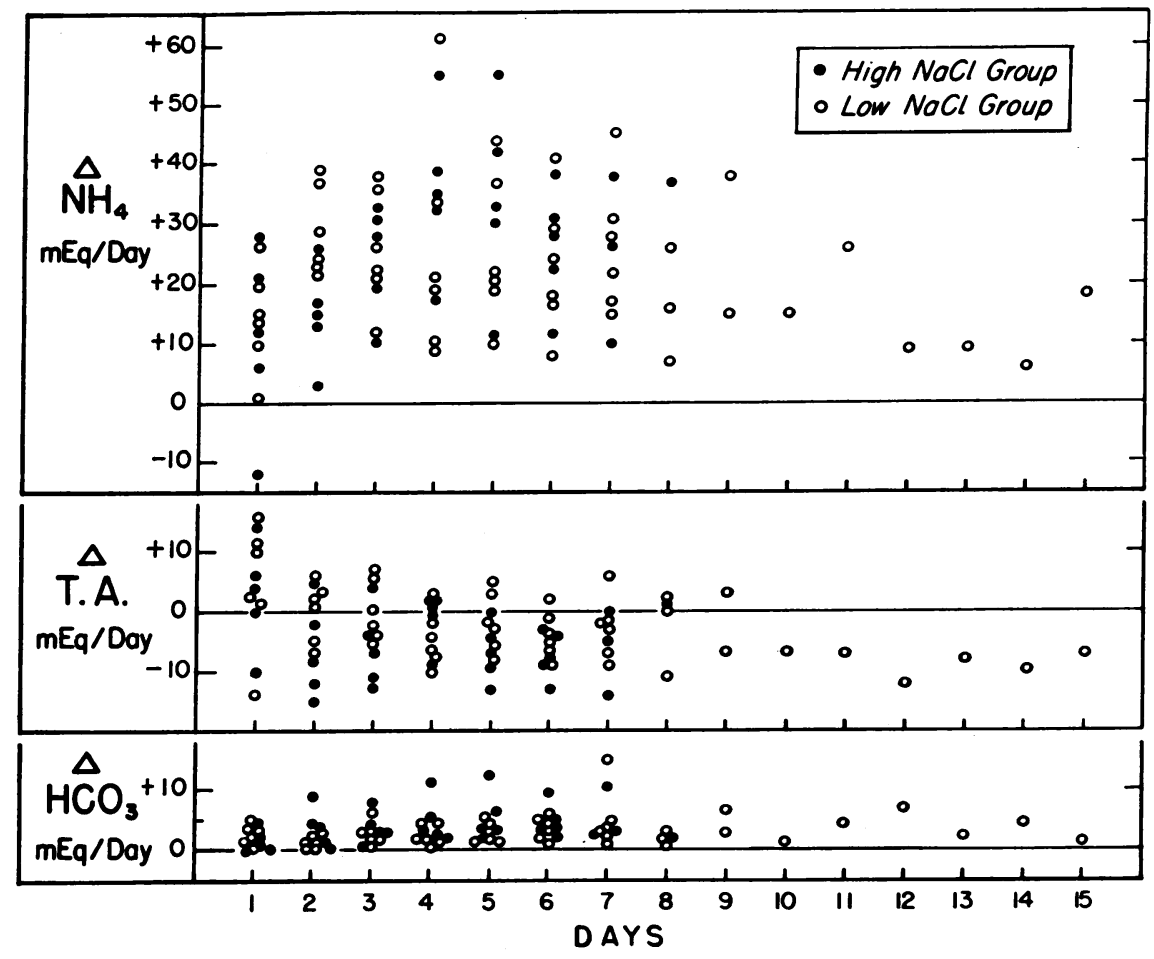

Fig. 7. Changes in the excretion of ammonium, titratable ACid, and bicarBONATE IN BOTH THE HIGH- AND LOW-SALT GROUPS DURING EXPOSURE TO A HIGH $\mathrm{CO}_{2}$ ATMOSPHERE. The values represent changes from the mean daily excretion during the control period. 

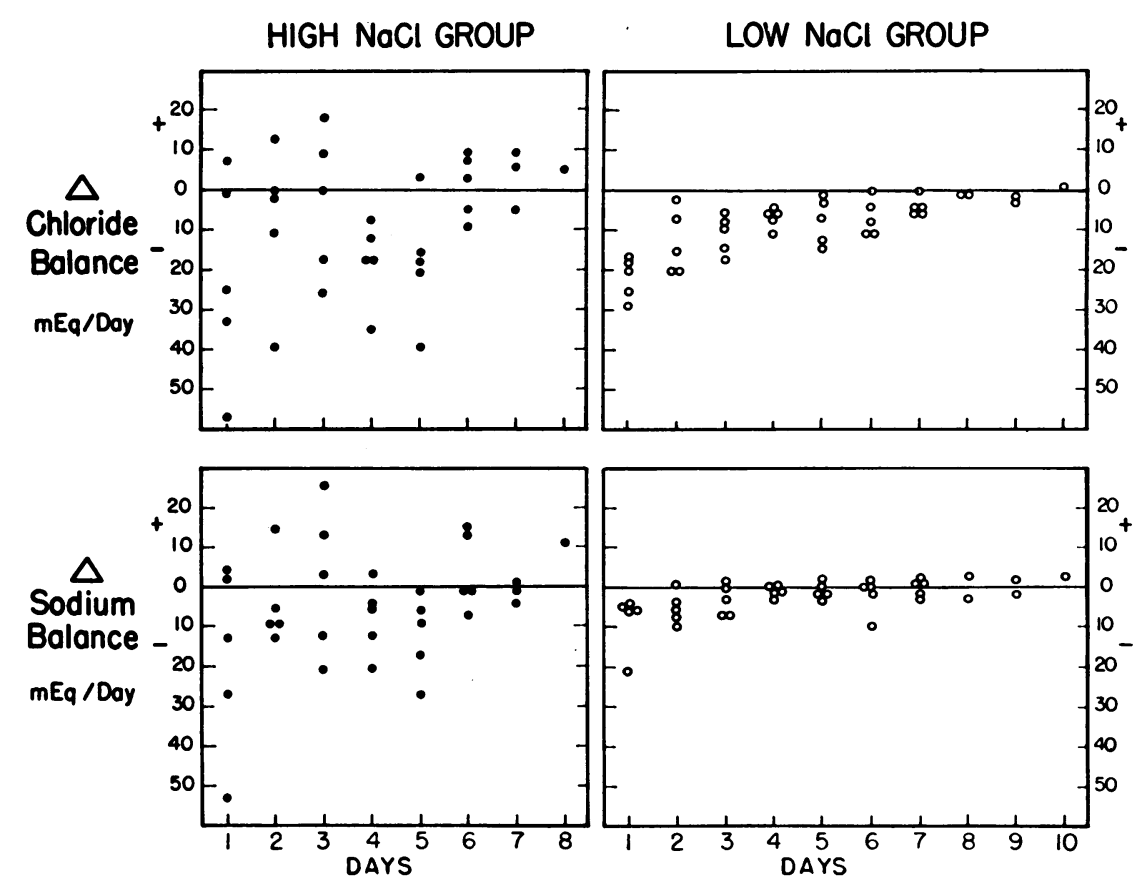

Fig. 8. Changes in Chloride AND SODIUM BALANCE DURING EXPOSURE TO A High $\mathrm{CO}_{2}$ ATmosphere. The values for the high-salt group represent changes from the mean daily balance during the control period. For the low-salt group, changes are calculated from the values for the last day of the control period, since earlier in the control period the urinary excretion was falling steadily.

control level toward the end of a week in $\mathrm{CO}_{2}$. Table III shows that cumulative $\Delta$ chloride balance ranged from -41 to -119 in 9 of the 10 dogs and was not significantly different in the two dietary groups.

Urinary sodium excretion (Figure 8) was increased initially in every dog except two (these were the two dogs in which all the changes in urinary electrolyte composition were delayed). The dogs on a low sodium chloride intake came into approximate daily sodium balance by the fourth day of exposure to $\mathrm{CO}_{2}$. In the high-salt group the pattern of sodium excretion varied widely, but by the sixth day all animals had returned to control levels of excretion. Table III shows that the cumulative $\Delta$ sodium balance for the entire $\mathrm{CO}_{2}$ period was usually somewhat negative, but in only 2 dogs (both of the high-salt group), was this deficit substantial. In no dog was sodium balance significantly positive. Cumulative chloride loss regularly exceeded the cumulative sodium loss. The excess chloride calculated from the ratio of the concentrations of these two ions in the extracellular fluid is shown in Table III. Expressed in this way, it is apparent that a substantial selective depletion of chloride occurred in all but one animal.

The plasma potassium, which at the end of the control period ranged from 3.5 to $4.6 \mathrm{mEq}$ per $\mathrm{L}$, showed no consistent trend in either dietary group during the $\mathrm{CO}_{2}$ period. During the control period all the dogs had remained approximately in potassium balance. On the first day in $\mathrm{CO}_{2}$ all dogs except two increased potassium excretion over the control level by amounts ranging from 25 to $65 \mathrm{mEq}$. (The exceptions were the two dogs in which all the changes in urinary electrolyte composition were delayed.) These figures were not appreciably changed by correction for nitrogen balance. During the rest of the $\mathrm{CO}_{2}$ period, the potassium excretion fell to the control level or below in 4 of the 5 dogs in each dietary group. In these dogs, the $\Delta$ potassium balance, corrected for nitrogen balance, ranged from -18 to $+36 \mathrm{mEq}$ (Table III). In the remaining dog in each group (Dogs D and G) the 
excretion remained somewhat elevated and cumulative $\Delta$ potassium balance was significantly negative, even after correction for nitrogen balance.

Urinary phosphate output rose significantly on the first day of exposure to $\mathrm{CO}_{2}$ in 8 dogs (the exceptions were the two dogs in which all the changes in urinary electrolyte excretion were delayed) by increments ranging from 9 to 25 mmoles. On subsequent days, in the majority of dogs, there was a persistent excess of phosphate excretion over control values. The dogs in which this excess was greatest were also those in which nitrogen balance was most strongly negative. In the dogs which remained in nitrogen balance, phosphate excretion returned to the control range after the first day. Plasma phosphate was estimated at intervals during the study in several dogs and showed no consistent change.

3. Nitrogen, sulfate, and organic acids. In most dogs of both the high- and low-salt groups, nitrogen excretion rose, with the result that $\Delta$ mean daily nitrogen balance during the $\mathrm{CO}_{2}$ period averaged approximately $-1.5 \mathrm{~g}$ in both dietary groups (Table III). The excretion of organic acids tended to increase, as illustrated in Figures 2 and 4 , but the changes were small and there was no significant difference between the two dietary groups. The rise in organic acid excretion was greatest in those animals whose nitrogen balance was most strongly negative. Sulfate excretion was measured in 3 low-salt and 3 highsalt dogs. In most instances there was an increase in sulfate excretion of 5 to $20 \mathrm{mEq}$ per day. These changes also appeared to correlate with changes in nitrogen balance.

4. Interrelationship of changes in certain urinary constituents on the first day. Figure 9A relates the increments in sodium and chloride excretion. It will be seen that the ratio of $\Delta$ chloride excretion to $\Delta$ sodium excretion was usually greater than $1: 1.3$, which is the approximate ratio of the concentrations of these electrolytes in the extracellular fluid (ECF) represented by the dashed line. It will be noted that in 2 dogs
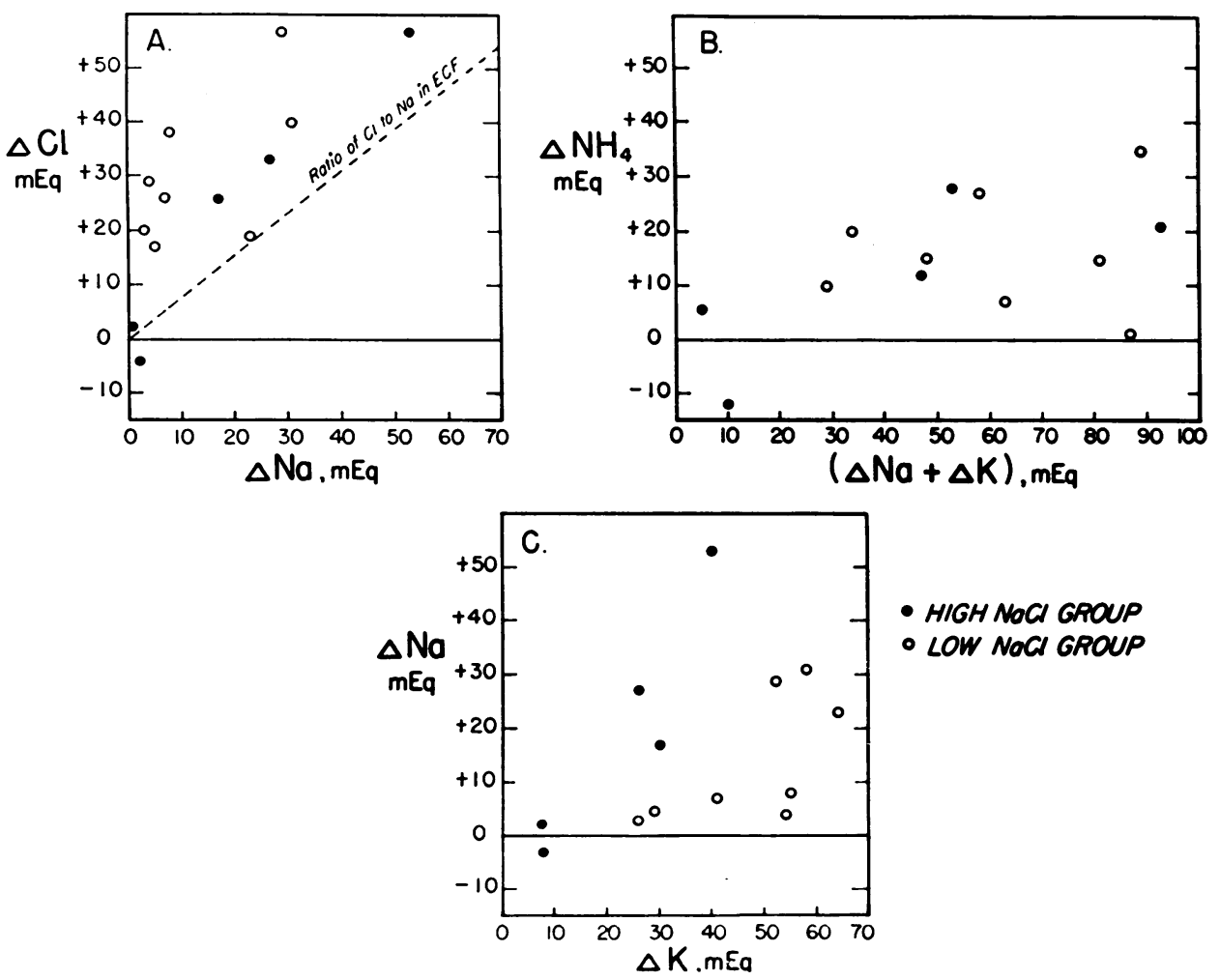

Fig. 9. Interkelationship OF Changes in CERTAin URINARy CONSTItUents during the FIRST dAY OF EXPOSURE TO A High $\mathrm{CO}_{2}$ ATMOSPhere. Data are included from 2 low-salt dogs which were not studied after the first day of exposure. 
from the high-salt group the changes in electrolyte excretion on the first day were negligible, as mentioned earlier.

Figure 9B relates the increment in ammonium excretion to the sum of the increments in sodium and potassium excretion. It will be seen that $\Delta$ ammonium excretion did not appear to be a function of $\Delta$ sodium plus potassium, and therefore was, in effect, unrelated to the magnitude of the total cation diuresis. There was, furthermore, no evidence that either parameter was influenced by the salt intake.

Figure 9C relates the increments in sodium and potassium excretion. In the low-salt group, $\Delta$ potassium excretion regularly exceeded $\Delta$ sodium excretion, comprising at least 60 per cent of $\Delta$ sodium plus potassium. Indeed, a significant natriuresis was seen in this group only when the loss of potassium was large (50 to $65 \mathrm{mEq}$ ). When any of the 3 high-salt dogs is compared with a low-salt dog whose potassium loss was similar, it appears that the high-salt dog lost more sodium; but, with only three pertinent observations in the high-salt group, the data must be interpreted with caution.

5. Miscellaneous data. During the $\mathrm{CO}_{2}$ period the weight change for the high-salt group averaged $-0.5 \mathrm{~kg}$, and for the low-salt group, $-1.5 \mathrm{~kg}$. The hematocrit showed no consistent change.

The electrolyte losses in the stools were not significantly different in the control and $\mathrm{CO}_{2}$ periods. In both groups the daily loss of sodium averaged about $4 \mathrm{mEq}$ per day. The loss of potassium averaged 1 in the high-salt group, and 6 $\mathrm{mEq}$ per day in the low-salt group. The chloride loss was about $1 \mathrm{mEq}$ per day in both groups.

\section{DISCUSSION}

These studies indicate that adaptation to chronic respiratory acidosis in the dog is a gradual process, is uninfluenced by the presence or absence of sodium chloride in the diet, and leads to only incomplete correction of the extracellular hydrogen ion concentration. Specifically, the data show a rise in plasma bicarbonate concentration over 6 or 7 days-independent of the sodium chloride intake-followed by a plateau which falls short, by 5 to $10 \mathrm{mEq}$ per $\mathrm{L}$, of the level neces- sary to restore the normal ratio of bicarbonate to carbonic acid.

The initial steep ascent in bicarbonate concentration, which usually comprised half or more of the final elevation, was often achieved with little or no increase in renal acid excretion. The increment in bicarbonate must, therefore, have been due largely to tissue buffering, a mechanism whose effectiveness has previously been demonstrated in the nephrectomized $\operatorname{dog}(6)$ and which is now seen to serve an important function even when the kidneys are intact. Calculation of the red blood cell contribution to the buffering process ( 7$)$ indicates that no more than one-third of the bicarbonate could have been derived from this source, and it follows that other tissues, such as muscle or bone, must have made the major contribution to the initial rise in extracellular bicarbonate. However, after the first day the cumulative increment in urinary net acid excretion was usually much greater than would be required to account for the concomitant increase of bicarbonate in the extracellular fluid. It may well be that the excess bicarbonate generated in the kidneys during this phase was consumed in the neutralization of hydrogen ions initially buffered in the cells. ${ }^{1}$ Such a restoration of cellular buffer capacity might be expected, since a rise in extracellular bicarbonate concentration will produce a favorable gradient for the movement of hydrogen ions out of cells. However, it should be noted that this interpretation rests upon the assumption that the endogenous acid load was constant. In view of the negative nitrogen balance and increased excretion of organic acids and sulfate which regularly occurred during hypercapnia, it seems likely that, in fact, the endogenous acid load increased, and to this extent the augmentation of renal acid excretion cannot be considered as contributing to the compensation of the respiratory acidosis. Until means of computing the net acid or alkaline load resulting from tissue breakdown become available,

${ }^{1}$ For convenience the internal changes in buffer stores have been expressed in terms of hydrogen ion movement. However, the data do not permit any distinction to be made between the transfer of hydrogen in one direction and the transfer of bicarbonate or hydroxyl ions in the other. The effect on extracellular bicarbonate concentration will, of course, be the same in each case. 
no final interpretation of the observed increase in renal acid excretion will be possible.

In each animal the rise in plasma bicarbonate was accompanied by a nearly equal fall in chloride. The cumulative increment in chloride excretion was of an order of magnitude sufficient to account for the fall ${ }^{2}$ in plasma concentration-an observation which has also been made in the rat (1). How a high $\mathrm{CO}_{2}$ tension induces the kidney to reject chloride is obscure. As has previously been suggested (1), it is possible that the chloruresis is due to a primary effect of the high $\mathrm{pCO}_{2}$ in accelerating hydrogen transfer into the glomerular filtrate, an action that would reduce the electrical gradient along which chloride is thought to move passively. Alternatively, the elevation of $\mathrm{pCO}_{2}$ might have the direct effect of lowering the permeability of the tubular epithelium to chloride. If this were so, the diminished reabsorbability of chloride might in itself contribute to the accelerated transfer of hydrogen ions into the glomerular filtrate (3) and thus to the increased reabsorption of bicarbonate. Another possibility is that hypercapnia depresses the proximal reabsorption of sodium and, hence, of chloride. If, in turn, some of the sodium were then exchanged in the distal tubule for potassium and ammonium, a selective urinary loss of chloride would result. Some insight into the interrelationship of chloride and hydrogen ion movement is provided by observations during recovery from chronic respiratory acidosis (5).

In addition to the changes in renal acid and chloride excretion, there were significant alterations in the excretion of other electrolytes. On the first day in the $\mathrm{CO}_{2}$ atmosphere, a cation diuresis occurred, which consisted largely of potassium in the low-salt group and of both sodium and potassium in the high-salt animals. It is not clear whether the cation increment was a consequence of displacement of these ions from cells [analogous to that which occurs in the nephrec-

\footnotetext{
${ }^{2}$ In Dogs $\mathrm{K}$ and $\mathrm{J}$ the initial fall in serum chloride concentration occurred without significant chloruresis. This hypochloremia can, in part, be attributed to the transfer of chloride into red blood cells, but the magnitude of the fall suggests that there was, in addition, a movement of sodium and water from other tissues into the extracellular space. By the end of the study, however, these animals had lost sufficient chloride to fully account for their hypochloremia.
}

tomized dog (6)] or whether the kidney was primarily responsible.

In the latter part of the study, some of the dogs with access to sodium showed a tendency to retain sodium, but in most animals a slight but significant deficiency persisted to the end of the study. This finding emphasizes that bicarbonate reabsorption can be greatly enhanced, without concomitant sodium retention, simply by increasing the proportion of bicarbonate and decreasing the proportion of chloride which is reabsorbed with the sodium.

After the first day of exposure to $\mathrm{CO}_{2}$ there was usually no potassium loss beyond that to be expected in association with the negative nitrogen balance. Indeed, the potassium deficit, corrected for nitrogen loss, was repaired in all but two of the animals, possibly as a result of the movement of hydrogen ions out of cells into the decreasingly acid extracellular fluid. In any event, the evidence that the specific deficit was restored by the end of the period of adaptation indicates that potassium deficiency cannot be invoked as a factor in the increased capacity for bicarbonate reabsorption. Moreover, in the two dogs in which significant potassium depletion persisted throughout the $\mathrm{CO}_{2}$ period, the renal response to hypercapnia did not appear to be modified in any way.

While the data demonstrate a suppression of titratable acid, a rise in urine $\mathrm{pH}$, and a slight increase in bicarbonate excretion throughout the period of exposure to $\mathrm{CO}_{2}$, it should be noted that the technique of the study may have introduced an artifact into the distribution of these acid-base moieties in the urine. Each day it was necessary to remove the animals for brief periods from the high $\mathrm{CO}_{2}$ atmosphere, and it is possible that a modest bicarbonate diuresis at this time was responsible for the continued excretion of alkali. The addition of bicarbonate to the 24-hour urine would, of course, also elevate its $\mathrm{pH}$ and diminish its content of titratable acid. Since only the first day's urine was formed during uninterrupted hypercapnia, it is only on this day that such an artifact can be excluded. However, the finding in a number of animals that bicarbonate excretion rose appreciably on the first day, despite the fact that plasma level had risen only moderately, suggests that the maximal ability of the kidney to conserve bicarbonate had not yet been achieved, a finding 
consistent with earlier observations on reabsorptive capacity of such animals during acute bicarbonate loading (8).

The response of the dog to exposure to a high $\mathrm{CO}_{2}$ atmosphere resembles that of the rat in that a large rise in plasma bicarbonate concentration is accompanied by an increase in the urinary output of chloride, ammonium, potassium, and phosphate $(1,2)$. The only striking difference is the much longer period required for adaptation in the dog. However, this latter characteristic provides valuable evidence that the various adaptive responses, which in the rat occur almost simultaneously, are not in fact interdependent. In addition to demonstrating the importance of tissue-buffering in the initial stages, the dog also shows a clear dissociation between the ammonium response and the increments in the output of chloride, phosphate, and potassium. These increments are largely confined to the first day, while the rise in ammonium excretion is usually delayed and always persistent. Thus, the ammonium response cannot be attributed to the anion diuresis. It is also a matter of some interest that the pattern of cation excretion is qualitatively similar to that seen after the induction of metabolic acidosis by the administration of ammonium chloride $(9,10)$. As in metabolic acidosis, there is initially a diuresis of sodium and potassium, and only later a rise in ammonium excretion.

\section{SUM M ARY}

Balance studies were carried out in 11 dogs exposed to an atmosphere of 11 to 13 per cent carbon dioxide for periods of 6 to 15 days. A consistent pattern of response was found, characterized by a sharp rise in plasma bicarbonate concentration during the first day of exposure, and a subsequent slower rise over the next 5 or 6 days to final concentrations ranging from 35 to 38 $\mathrm{mEq}$ per L. During the first day, when approximately one-half of the total rise in plasma bicarbonate occurred, there was often little or no increase in renal acid excretion, indicating that tissue buffers played a major role in the initial defense of the extracellular $\mathrm{pH}$. Subsequently, however, the increment in net acid excretion was far in excess of the amount required to account for the estimated increase in extracellular bicarbo- nate. It has been suggested that the excess of bicarbonate may well have been utilized in the neutralization of hydrogen ions diffusing from cells as the extracellular bicarbonate concentration rose. The plasma bicarbonate approached a plateau which fell short, by 5 to $10 \mathrm{mEq}$ per $\mathrm{L}$, of the level necessary for full compensation of the acidosis. The sodium chloride content of the diet appeared to exert no significant effect on the adaptive process.

The plasma chloride concentration varied in a virtually reciprocal fashion with the plasma bicarbonate concentration throughout the study. In each dog there was a chloruresis and a cumulative chloride loss of sufficient magnitude readily to account for the degree of hypochloremia. A clear dissociation was shown between the increments in chloride and in ammonium excretion.

On the first day in the $\mathrm{CO}_{2}$ atmosphere there was a marked increase in the excretion of potassium and phosphorus and a variable sodium diuresis. Subsequently, both sodium and potassium excretion returned toward or to the control level. At the end of the study there usually remained a slight deficit of sodium, but in most instances, after correction for changes in nitrogen balance, there was no evidence of potassium deficiency.

\section{REFERENCES}

1. Levitin, H., Branscome, W., and Epstein, F. H. The pathogenesis of hypochloremia in respiratory acidosis. J. clin. Invest. 1958, 37, 1667.

2. Carter, N. W., Seldin, D. W., and Teng, H. C. Tissue and renal response to chronic respiratory acidosis. J. clin. Invest. 1959, 38, 949.

3. Bank, N., and Schwartz, W. B. The influence of anion penetrating ability on urinary acidification and the excretion of titratable acid. J. clin. Invest. $1960,39,1516$.

4. Schwartz, W. B., Bank, N., and Cutler, R. W. P. The influence of urinary ionic strength on phosphate $\mathrm{pK}_{2}^{\prime}$ and the determination of titratable acid. J. clin. Invest. 1959, 38, 347.

5. Schwartz, W. B., Hays, R. M., Polak, A., and Haynie, G. D. Effects of chronic hypercapnia on electrolyte and acid-base equilibrium. II. Recovery, with special reference to the influence of chloride intake. J. clin. Invest. 1961, 40, 1238.

6. Giebisch, G., Berger, L., and Pitts, R. F. The extrarenal response to acute acid-base disturbances of respiratory origin. J. clin. Invest. 1955, 34, 231. 
7. Davenport, H. W. The ABC of Acid-base Chemistry: The Elements of Physiological Blood-gas Chemistry for Medical Students and Physicians, 4th ed. Chicago, Univ. of Chicago Press, 1958.

8. Sullivan, W. J., and Dorman, P. J. The renal response to chronic respiratory acidosis. J. clin. Invest. 1955, 34, 268.
9. Gamble, J. L., Blackfan, K. D., and Hamilton, B. A study of the diuretic action of acid producing salts. J. clin. Invest. 1924-25; 1, 359.

10. Sartorius, O. W., Roemmelt, J. C., and Pitts, R. F. The renal regulation of acid-base balance in man. IV. The nature of the renal compensations in ammonium chloride acidosis. J. clin. Invest. 1949, 28, 423. 